Short Note

\title{
(1R,5S)-6-(4-Methyl-2-oxo-2,5-dihydrofuran-3-yl)-3- phenyl-4-oxa-2,6-diazabicyclo[3.2.0]hept-2-en-7-one
}

\author{
Dong-Jun Fu 1,2, Victor Pham ${ }^{2}$, Matthew-Alexander Tippin ${ }^{2}$, Liankun Song ${ }^{2}$, Xiaolin $\mathrm{Zi}^{2}$, \\ En Zhang ${ }^{1}$ and Hong-Min Liu ${ }^{1, *}$ \\ 1 School of Pharmaceutical Sciences \& Collaborative Innovation Center of New Drug Research and Safety \\ Evaluation, Zhengzhou University, Zhengzhou 450001, China; zzufdj@sina.com (D.-J.F.); \\ zhangen@zzu.edu.cn (E.Z.) \\ 2 Department of Urology, University of California, Irvine, Orange, CA 92868, USA; victorp1@uci.edu (V.P.); \\ matthew.tippin@gmail.com (M.-A.T.); liankuns@uci.edu (L.S.); xzi@uci.edu (X.Z.) \\ * Correspondence: liuhm@zzu.edu.cn; Tel.: +86-371-67781739
}

Received: 11 August 2018; Accepted: 28 August 2018; Published: 30 August 2018

\begin{abstract}
Efficient large-scale and feasible industrial synthesis of the 1-oxacephem core structure from 6-aminopenicillanic acid (6-APA) has been reported for several decades. Via the industrial synthesis route, a byproduct (compound 9) containing a butenolide unit was purified and characterized by NMR and HRMS in this work. It is worth noting that compound 9 is an entirely new compound. Additionally, a plausible mechanism and effects on the formation of 9 by different Lewis acids were proposed. The discovery of compound $\mathbf{9}$ could improve the purity of this feasible industrial synthesis and provide considerable cost savings.
\end{abstract}

Keywords: industrial feasible synthesis; 6-APA; butenolide; 1-oxacephem

\section{Introduction}

Antibacterial substances are of great importance and necessity in treating infectious diseases caused by pathogenic bacteria [1-3]. Due to its unique antimicrobial activity and novel structure among the synthetic antibiotics, the 1-oxacephem core structure as an important pharmaceutical scaffold has attracted immense interest from medicinal chemists [4-6]. A variety of synthetic compounds prepared from the 1-oxacephem intermediate, including prominent antibiotics such as Flomoxef, Moxalactam, and OCP-9-176 (Figure 1), have a broad spectrum of activity against Gram-positive and Gram-negative aerobic and anaerobic bacteria [7-9].

A feasible industrial route by which to synthesize 1-oxacephem 8 in good yield starting from commercially available 6-aminopenicillanic acid (6-APA) (Figure 2) was reported by Nagata of the Shionogi company $[10,11]$. In this sophisticated method designed to retain all the carbon atoms, preparing epioxazolinoazetidinones having an unconjugated ester moiety at the $\beta$-lactam nitrogen was a breakthrough. However, byproducts of and probable mechanisms in this industrial synthesis of 1-oxacephem 8 have not been systematically explored. In this work, we focused on the byproduct 9 ((1R,5S)-6-(4-methyl-2-oxo-2,5-dihydrofuran-3-yl)-3-phenyl-4-oxa-2,6-diazabicyclo[3.2.0]hept-2-en-7-one). 
<smiles>[R]C1=C(C(=O)O[Tl])N2C(=O)C([R])([R])C2OC1</smiles><smiles>CO[C@]1(NC(=O)C(C(=O)O[Na])c2ccc(O)cc2)C(=O)N2C(C(=O)O[Na])=C(CSc3nnnn3C)CO[C@@H]21</smiles>

Moxalactam

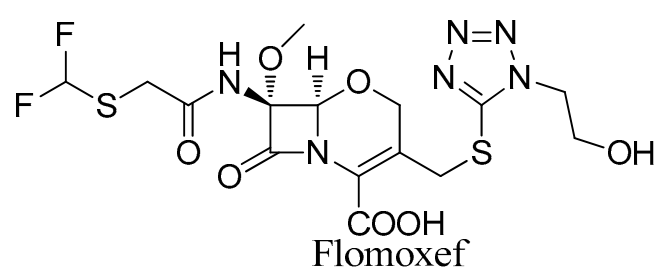<smiles>C[C@H]1O[C@@H](NC(=O)/C(=N/OC(C)(C(=O)O)C(=O)O)c2csc(N)n2)[C@H]2C(=O)N1C(C(=O)[O-])=C2CSc1cc[n+](C)cc1</smiles>

OCP-9-176

Figure 1. Synthetic 1-oxacephem antibiotics.<smiles>CC1(C)S[C@@H]2[C@H](N)C(=O)N2[C@H]1C(=O)O</smiles>

1, 6-APA<smiles>CC1(C)[C@H](C(=O)OCc2ccccc2)N2C(=O)[C@H](NC(=O)c3ccccc3)[C@H]2S1=O</smiles>

2<smiles>C=C(C)C(C(=O)OCc1ccccc1)N1C(=O)C2N=C(c3ccccc3)OC21</smiles>

3<smiles>C=C(CCl)[C@H](C(=O)OCc1ccccc1)N1C(=O)[C@@H]2N=C(c3ccccc3)O[C@H]21</smiles>

$4 \overline{\mathrm{COOCHPh}} 2$

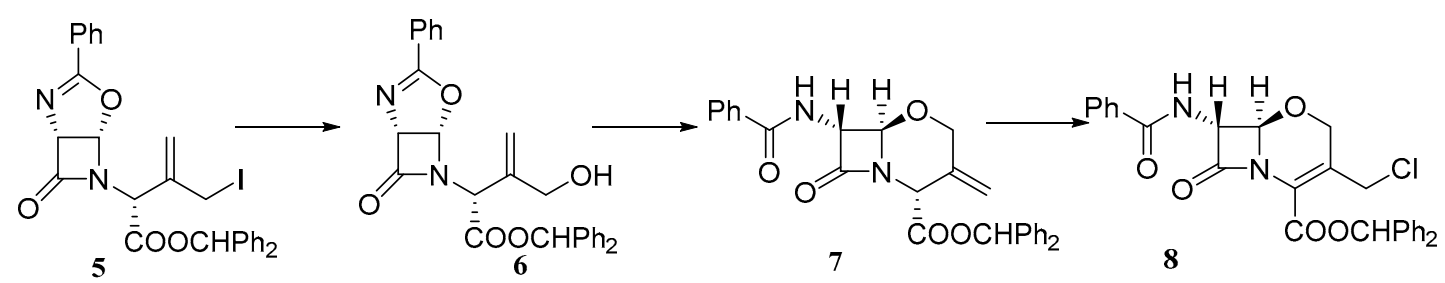

Figure 2. Feasible industrial synthesis of 1-oxacephem 8.

\section{Results and Discussion}

Intramolecular etherification proceeded from the less-hindered $\beta$ side with stereoselectivity to furnish a versatile exomethylene intermediate 7 in $79 \%$ yield and accompanied by a byproduct 9 in $15 \%$ yield. The probable mechanism which afforded the butenolide 9 catalyzed by boron fluoride ethyl ether involved two reactions: (a) an intramolecular transesterification and (b) isomerization of the double bond promoted by a Lewis acid (Scheme 1).

Systematic studies of the reaction conditions to obtain byproduct 9 in highest yield revealed that Lewis acids played key roles (Table 1 ). When the reaction was catalyzed by $\mathrm{BF}_{3} \cdot \mathrm{Et}_{2} \mathrm{O}$ and $\mathrm{Yb}(\mathrm{OTf})_{3}$, the major product was compound 7 (Table 1, entries 1 and 6) with yields of $90 \%$ and $56 \%$, respectively. Our best result was achieved with $\mathrm{BF}_{3} \cdot \mathrm{Et}_{2} \mathrm{O}$ at $25^{\circ} \mathrm{C}$, conditions in which 7 was formed in $90 \%$ yield, along with only a small amount of readily separable 9 (Table 1, entry 1). When the Lewis acid was changed to $\mathrm{LiCl}$ or $\mathrm{ZnCl}_{2}$, byproduct 9 was obtained as a dominant product (Table 1, entries 2, 3, 4).

To our surprise, when EtOH was used as the solvent instead of EtOAc (Table 1, entry 3), the yield of byproduct 9 increased to $92 \%$. These results suggested that ethyl alcohol and Lewis acid $\mathrm{LiCl}$ were suitable for this transformation to generate the byproduct 9 in an excellent yield. 


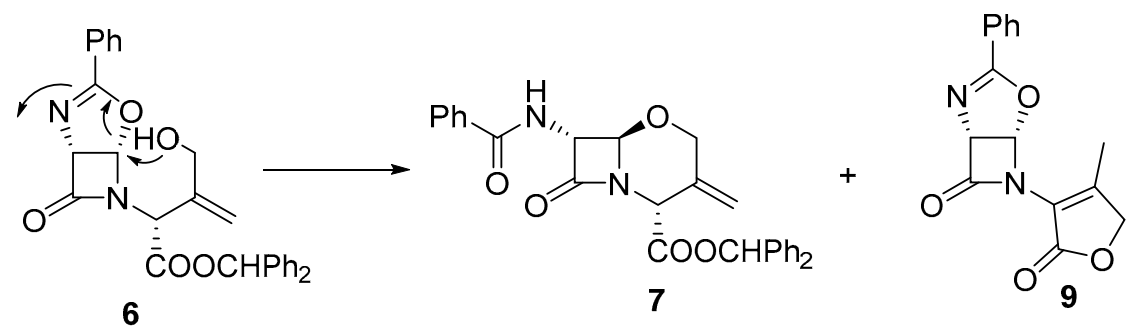

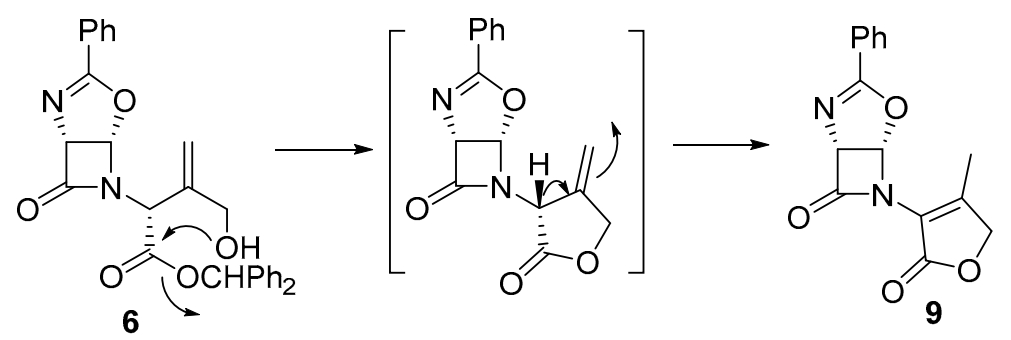

Scheme 1. The probable mechanism of formation of 9 catalyzed by a Lewis acid $\left(\mathrm{BF}_{3} \cdot \mathrm{Et}_{2} \mathrm{O}\right)$.

Table 1. Screening of the reaction conditions.

\begin{tabular}{cccccc}
\hline Entry & $\begin{array}{c}\text { Lewis Acid } \\
\mathbf{a}\end{array}$ & Temperature & Solvent & $\begin{array}{c}\text { Yields of } \mathbf{7} \\
\mathbf{b}\end{array}$ & $\begin{array}{c}\text { Yields of } \mathbf{9} \\
\mathbf{b}\end{array}$ \\
\hline 1 & $\mathrm{BF}_{3} \cdot \mathrm{Et}_{2} \mathrm{O}$ & $25^{\circ} \mathrm{C}$ & EtOAc & $90 \%$ & $1 \%$ \\
2 & $\mathrm{LiCl}$ & $25^{\circ} \mathrm{C}$ & EtOAc & $33 \%$ & $60 \%$ \\
3 & $\mathrm{LiCl}$ & $25^{\circ} \mathrm{C}$ & EtOH & $1 \%$ & $92 \%$ \\
4 & $\mathrm{ZnCl}_{2}$ & $25^{\circ} \mathrm{C}$ & EtOAc & $29 \%$ & $65 \%$ \\
5 & $\mathrm{FeCl}_{3}$ & $25^{\circ} \mathrm{C}$ & EtOAc & $46 \%$ & $42 \%$ \\
6 & $\mathrm{Yb}(\mathrm{OTf})_{3}$ & $25^{\circ} \mathrm{C}$ & EtOAc & $56 \%$ & $36 \%$ \\
\hline \multicolumn{6}{c}{ a 1 mol \% Lewis acid was used. ${ }^{\mathrm{b}}$ Isolated yields. }
\end{tabular}

\section{Materials and Methods}

\subsection{General Information}

All the reactions were monitored by thin-layer chromatography. The byproducts were purified by column chromatography over silica gel (Qingdao Haiyang Chemical Co., 200-300 mesh, Qingdao, China). Melting points were determined on a Beijing Keyi XT4A apparatus (Beijing synthware glass, Beijing, China). All NMR spectra were recorded with a Bruker DPX $400 \mathrm{MHz}$ spectrometer (Agilent, Santa Clara, CA, USA) with TMS as the internal standard. Chemical shifts are given as $\delta$ ppm values relative to TMS. Mass spectra (MS) were recorded on an Esquire 3000 mass spectrometer (Varian, Palo Alto, CA, USA) by electrospray ionization (ESI).

3.2. Synthesis of (1R,5S)-6-(4-Methyl-2-oxo-2,5-dihydrofuran-3-yl)-3-phenyl-4-oxa-2,6-diazabicyclo[3.2.0] hept-2-en-7-one (9)

A solution of $\mathrm{LiCl}(1 \mathrm{~mol} \%)$ was added to intermediate 6 ( $1 \mathrm{eq}, 1 \mathrm{~g})$ in $\mathrm{EtOH}(10 \mathrm{~mL})$ in a round-bottom flask and reacted at room temperature for $7 \mathrm{~h}$. The reaction system was evaporated to give a residue, which was purified by silica gel flash column chromatography (EtOAc $/ n$-hexane $=1: 7$ ) to afford the product 9, yield $92 \%$. White solid; m.p. $199.2-200.3{ }^{\circ} \mathrm{C} ;[\alpha]_{\mathrm{D}}^{25}+18.9^{\circ}\left(\mathrm{C} 1.05, \mathrm{CHCl}_{3}\right)$; ${ }^{1} \mathrm{H}-\mathrm{NMR}\left(400 \mathrm{MHz}, \mathrm{CDCl}_{3}\right) \delta 8.02(\mathrm{~d}, J=7.4 \mathrm{~Hz}, 2 \mathrm{H}), 7.54(\mathrm{t}, J=7.4 \mathrm{~Hz}, 1 \mathrm{H}), 7.45(\mathrm{t}, J=7.6 \mathrm{~Hz}, 2 \mathrm{H})$, $6.81(\mathrm{~d}, J=3.3 \mathrm{~Hz}, 1 \mathrm{H}), 5.45(\mathrm{~d}, J=3.3 \mathrm{~Hz}, 1 \mathrm{H}), 4.73(\mathrm{~s}, 2 \mathrm{H}), 2.18(\mathrm{~s}, 3 \mathrm{H}) ;{ }^{13} \mathrm{C}-\mathrm{NMR}\left(100 \mathrm{MHz}, \mathrm{CDCl}_{3}\right) \delta$ 
168.64, 167.16, 163.73, 148.48, 132.40, 128.59, 128.50, 126.73, 119.77, 84.70, 82.26, 71.77, 13.17; HRMS (ESI): $m / z$ calcd for $\mathrm{C}_{15} \mathrm{H}_{12} \mathrm{~N}_{2} \mathrm{O}_{4}(\mathrm{M}+\mathrm{H})^{+}$, 285.0875; found, 285.0880 .

\section{Conclusions}

In summary, byproduct 9 was obtained in the industrial synthesis of the 1-oxacephem core structure from 6-aminopenicillanic acid. To the best of our knowledge, this is the first report about the byproduct 9 . We explored the effects on the formation of azetidinone-fused butenolide 9 caused by different Lewis acids and explored its probable mechanism of formation. The study of byproduct $\mathbf{9}$ is valuable for efficient large-scale and feasible industrial synthesis of the 1-oxacephem core structure.

Supplementary Materials: Supplementary materials are available online.

Author Contributions: D.-J.F. and E.Z. designed and synthesized the compounds. V.P., M.-A.T., L.S. and X.Z. revised the manuscript. D.-J.F. wrote the manuscript and H.-M.L. was responsible for the correspondence of the manuscript. All authors read and approved the final manuscript.

Funding: Thanks for the funding of Zhengzhou University.

Acknowledgments: This work was supported by MEDCHEMEXPRESS. Our thanks to the MCE Award for Scientists Promoting Biology and Medicine Research, and to the CSC scholarship.

Conflicts of Interest: The authors declare no conflict of interest.

\section{References}

1. Zhao, Z.H.; Zhang, X.X.; Jin, L.L.; Yang, S.; Lei, P.S. Synthesis and antibacterial activity of novel ketolides with 11,12-quinoylalkyl side chains. Bioorg. Med. Chem. Lett. 2018, 28, 2358-2363. [CrossRef] [PubMed]

2. Zhang, L.; Wang, L.; Yi, L.; Wang, X.; Zhang, Y.; Liu, J.; Guo, X.; Liu, L.; Shao, C.; Xin, L. A novel antimicrobial substance produced by Lactobacillus rhamnous LS8. Food Control 2016, 73, 754-760. [CrossRef]

3. Journal, E.; Pathology, P. Biological control of grapevine crown gall: Purification and partial characterisation of an antibacterial substance. Eur. J. Plant. Pathol. 2013, 124, 427-437.

4. Hakimelahi, G.H.; Li, P.C.; Moosavimovahedi, A.A.; Chamani, J.; Khodarahmi, G.A.; Ly, T.W.; Valiyev, F.; Leong, M.K.; Hakimelahi, S.; Shia, K.S. Application of the Barton photochemical reaction in the synthesis of 1-dethia-3-aza-1-carba-2-oxacephem: A novel agent against resistant pathogenic microorganisms. Org. Biomol. Chem. 2003, 1, 2461-2467. [CrossRef] [PubMed]

5. Kobayashi, Y.; Doi, M.; Nagata, H.; Kubota, T.; Kume, M.; Murakami, K. The $7 \alpha$-methoxy substituent in cephem or oxacephem antibiotics enhances in vivo anti-Helicobacter felis activity in mice after oral administration. J. Antimicrob. Chemother. 2000, 45, 807-811. [CrossRef] [PubMed]

6. Tombor, Z.; Greff, Z.; Nyitrai, J.; Kajtár-Peredy, M. Simple and condensed $\beta$-lactams, XIX. Synthesis of some new 7-acylamino-2-iso-oxacephem-4-carboxylic acids. Eur. J. Org. Chem. 2010, 1995, 825-835. [CrossRef]

7. Lee, C.H.; Chen, I.L.; Li, C.C.; Chien, C.C. Clinical benefit of ertapenem compared to flomoxef for the treatment of cefotaxime-resistant Enterobacteriaceae bacteremia. Infect. Drug Resist. 2018, 11, 257-266. [CrossRef] [PubMed]

8. Singh, B.R. Moxalactam is not more active on extended spectrum $\beta$-lactamase (ESBL) producing bacteria than on non-ESBL producers. Infect. Drug Resist. 2018, 11, 427-429. [CrossRef] [PubMed]

9. Shibahara, S.; Okonogi, T.; Murai, Y.; Kudo, T.; Yoshida, T.; Kondo, S.; Christensen, B.G. Synthesis of a novel 2-beta-methyl-1-oxacephalosporin, OCP-9-176. J. Antibiot. 1988, 41, 1154-1157. [CrossRef] [PubMed]

10. Otsuka, H.; Nagata, W.; Yoshioka, M.; Narisada, M.; Yoshida, T.; Harada, Y.; Yamada, H. Discovery and development of Moxalactam (6059-S): The chemistry and biology of 1-oxacephems. Med. Res. Rev. 1981, 1, 217-248. [CrossRef] [PubMed]

11. Yoshioka, M.; Tsuji, T.; Uyeo, S.; Yamamoto, S.; Aoki, T.; Nishitani, Y.; Mori, S.; Satoh, H.; Hamada, Y.; Ishitobi, H.; et al. Stereocontrolled, straightforward synthesis of 3-substituted methyl $7 \alpha$-methoxy-1-oxacephems. Tetrahedron Lett. 1980, 21, 351-354. [CrossRef] 